\title{
Reduction in life expectancy in Brazil after COVID-19
}

\author{
Marcia C. Castro $\mathbb{1}^{1 凶}$, Susie Gurzenda $\mathbb{1}^{1}$, Cassio M. Turra $\mathbb{D}^{2}$, Sun Kim $\circledast^{1}$, Theresa Andrasfay $\mathbb{(}^{3}$ and \\ Noreen Goldman ${ }^{4}$
}

Brazil has been heavily affected by coronavirus disease 2019 (COVID-19). In this study, we used data on reported total deaths in 2020 and in January-April 2021 to measure and compare the death toll across states. We estimate a decline in 2020 life expectancy at birth $\left(e_{0}\right)$ of 1.3 years, a mortality level not seen since 2014 . The reduction in life expectancy at age $65\left(e_{65}\right)$ in 2020 was 0.9 years, setting Brazil back to 2012 levels. The decline was larger for males, widening by $9.1 \%$ the female-male gap in $e_{0}$. Among states, Amazonas lost 60.4\% of the improvements in $e_{0}$ since 2000. In the first 4 months of 2021, COVID-19 deaths represented 107\% of the total 2020 figures. Assuming that death rates would have been equal to 2019 all-cause rates in the absence of COVID-19, COVID-19 deaths in 2021 have already reduced $e_{0}$ in 2021 by 1.8 years, which is slightly larger than the reduction estimated for 2020 under similar assumptions.

A s of 9 June 2021, COVID-19 has officially claimed more than 3.7 million lives worldwide, $48 \%$ of which were in the Americas. The actual death toll is likely to be higher due to deficient surveillance, limited testing that prevented proper diagnosis, issues of compliance with protocols for reporting a suspected COVID-19 death and location of the death (for example, at home $)^{1,2}$. Together, the United States and Brazil account for $28 \%$ of the world's death toll and 59\% of the death toll in the Americas. In both countries, the pandemic response in 2020 was disparate regionally, with lamentable national coordination ${ }^{3,4}$, resulting in a high and unequal mortality burden ${ }^{5,6}$. Brazil continues to face a challenging situation. April 2021 was the deadliest month since the pandemic began: nine capital cities reported more deaths than births, and, by 25 April, the number of COVID-19 deaths in 2021 surpassed that reported in 2020 .

The consequences of that death toll can be measured by $e_{0}$, which indicates the average number of years a newborn would be expected to live if born in a specific year and subject to the prevailing mortality rates in that year throughout life. Changes in $e_{0}$ can reflect differences in expected longevity between two periods, such as before versus during a pandemic. For example, the 1918 influenza pandemic was estimated to have reduced $e_{0}$ in the United States by $7-12$ years ${ }^{7}$. Mortality due to COVID-19 is estimated to have reduced $e_{0}$ in the United States by 1.13 years, setting it back to values observed in 2003 (ref. $^{8}$ ).

Similarly, given the higher risk of dying from COVID-19 at older ages ${ }^{5}$, the death toll can be measured by $e_{65}$, defined as the average number of years that a 65 -year-old person would be expected to live if subject to the underlying mortality rates for ages 65 and above in a specific year.

Considering the large COVID-19 death toll in Brazil, with marked regional inequalities, our goal was to quantify the loss in $e_{0}$ and $e_{65}$ in 2020 and in the first 4 months of 2021 due to the pandemic. Estimates are presented by sex and state, and we measured and compared changes across states and in female-male gaps in life expectancy. A summary of findings and implications of these estimates is shown in Table 1.

Before COVID-19, $e_{0}$ in Brazil lagged behind many countries in Asia, Europe and the Americas. In Latin America, at least four countries experienced secular mortality declines at earlier dates: Argentina, Uruguay, Costa Rica and Cuba9. Between 1945 and $2020, e_{0}$ in Brazil increased from 45.5 years to 76.7 years $^{10}$, an average of almost 5 months per calendar year. Similarly to Brazil, many other countries in Latin America experienced a relatively fast pace of mortality improvement during this period, benefitting from the public health and medical progress of their forerunners ${ }^{9,11}$.

\section{Results}

Decline in $\boldsymbol{e}_{0}$ and $\boldsymbol{e}_{65}$ in 2020. Based on the total number of deaths reported in Brazil in 2019 and 2020, we constructed period life tables and calculated the difference in life expectancy between 2019 and 2020 by state and sex (Methods). We estimated a reduction of 1.31 years in $e_{0}$ from 2019 to 2020 (Fig. 1a, Supplementary Table 1 and Methods), with a larger drop for males (1.57 years) than females ( 0.95 years). The highest absolute and relative decline among states was estimated for Amazonas (3.46 years), followed by Amapá (3.18 years) and Pará (2.71 years), all in the North region. Rio Grande do Sul, in the South, was the only state with an estimated increase in $e_{0}$ from 2019 to 2020 for both sexes ( 0.07 years) but a decline for males of 0.11 years.

We also estimated changes in $e_{65}$ (Fig. $1 \mathrm{~b}$ and Supplementary Table 2$)^{5}$. The estimated decline for Brazil was 0.94 years for both sexes, 0.66 years for females and 1.17 years for males. Across states, the largest declines were estimated for Amazonas (3.14 years), Amapá (2.46 years) and Pará (2.44 years). $e_{65}$ declined by a larger percentage for males than females in all states, reflecting men's higher risks of dying from COVID-19 (ref. ${ }^{5}$ ). In Amazonas, male $e_{65}$ was estimated to decline by $20 \%$ from 2019 to 2020 .

On average, larger declines in $e_{0}$ and $e_{65}$ were estimated in the North regions and smaller in the South regions (Fig. 1c), broadly mirroring 
the patterns across states (Fig. 1d). States in the North and Northeast have the worst indicators of income inequality, poverty, access to infrastructure and availability of physicians and hospital beds ${ }^{12,13}$. In the Northeast, however, the estimated decreases in life expectancy in 2020 are smaller than in the North. Governors in that region imposed the most rigorous measures of physical distancing, in direct opposition to recommendations from the President ${ }^{14}$. The South was the last region to be severely hit by COVID-19 in 2020 (ref. ${ }^{15}$ ), producing the relatively small estimates of life expectancy decline.

Following multiple decrement life table methods previously used to measure the effect of COVID-19 on life expectancy ${ }^{8,16,17}$, we calculated two additional sets of estimates of life expectancy decline: (1) the difference between 2020 life expectancy estimated above and a scenario in which COVID-19 mortality has been eliminated from 2020 (DT20; Supplementary Tables 3 and 4 and Methods); and (2) the difference between 2019 life expectancy estimated from 2019 death records and a scenario in which 2019 all-cause mortality has been inflated to include COVID-19 mortality (DT19; Supplementary Tables 5 and 6 and Methods). Both methods resulted in larger estimates of life expectancy decline compared to the difference between 2019 and 2020 period life tables (Supplementary Tables 1 and 2): for example, for Brazil (both sexes), the decline in $e_{0}$ was estimated at 1.92 years (DT20) and 1.67 years (DT19) versus 1.31 years (difference between 2019 and 2020 life tables).

The main results presented in the text are based on differences between the 2019 and 2020 life tables, for two primary reasons. First, differences in these period life expectancies capture both direct and indirect mortality effects of COVID-19 in 2020. Death rates from non-COVID-19 causes in 2020 likely changed between 2019 and 2020, decreasing for some causes (for example, from reduced exposure to other infections) and increasing in others (for example, from delayed or foregone healthcare or overburdening of the healthcare system). DT19 and DT20 assess the effect of including and excluding, respectively, only deaths for which COVID-19 was listed as the underlying cause on the death certificate. Second, in contrast to DT19 and DT20, the method based on the difference in life expectancy between 2019 and 2020 makes no assumption about independence of causes of death (that is, that the risks of dying from other causes are unaffected by the addition or elimination of COVID-19 mortality), an assumption that was almost certainly violated during the pandemic.

Changes in the sex and state gaps in life expectancy. We compared the gap in life expectancy between males and females in the period life tables constructed for 2019 and 2020 (Methods). Our results point to an overall widening of the female-male gap in $e_{0}$ of 0.6 years in Brazil (9.1\% increase). In Amapá, the female-male gap is estimated to increase by 2.1 years, the highest among the states (Fig. 2a and Supplementary Table 7). Larger relative female-male gaps were estimated for $e_{65}$-an increase of $16.3 \%$ in 2020 in Brazil and a 107\% increase in 2020 in Amapá.

We also calculated state inequalities in life expectancy, measured as the difference between the lowest and the highest state life expectancy, to assess changes due to COVID-19 (Methods). The state gap remained roughly the same for both $e_{0}$ and $e_{65}$ (Fig. 2b). Also, the states with extreme values changed only for $e_{65}$ for both sexes, with the lowest shifting from Roraima in 2019 to Amazonas in 2020. As high life expectancies are predominantly in the South region and the lowest are in the North, these results suggest that COVID-19 mortality reproduced regional inequalities, reflecting the pandemic's disproportionate burden among vulnerable groups ${ }^{5}$ but also spatial patterns of COVID-19 spread $^{18}$.

Effect on improvements in life expectancy from 2000 to 2020. We quantified the effect of COVID-19 on reversing the progress in mortality reduction since 2000 (Methods). Of the gains achieved

\begin{tabular}{|c|c|}
\hline Background & $\begin{array}{l}\text { Brazil's national response to the COVID-19 } \\
\text { pandemic has been distressing, resulting in a } \\
\text { high and unequal mortality burden. The country } \\
\text { comprises only } 2.7 \% \text { of the world's population } \\
\text { but } 12.7 \% \text { of COVID-19 deaths worldwide (as of } 9 \\
\text { June } 2021 \text { ). That death toll will result in substantial } \\
\text { reductions in life expectancy in } 2020 \text { and } 2021 \text {, } \\
\text { with marked differences by sex and state. }\end{array}$ \\
\hline $\begin{array}{l}\text { Main findings and } \\
\text { limitations }\end{array}$ & $\begin{array}{l}\text { Several methods were used to estimate the } \\
\text { decline in life expectancy at birth and at age } \\
65 \text {. We show that } 2020 \text { life expectancy in the } \\
\text { presence of COVID- } 19 \text { is equivalent to mortality } \\
\text { levels observed in Brazil as far back as } 20 \text { or } \\
\text { more years in some states. The effect on } 2021 \text { life } \\
\text { expectancy is estimated to be even larger. Despite } \\
\text { the assumptions underlying these estimates, it is } \\
\text { unquestionable that the death toll from COVID-19 } \\
\text { in Brazil has been catastrophic. }\end{array}$ \\
\hline Policy implications & $\begin{array}{l}\text { Our findings show that life expectancy in Brazil } \\
\text { declined substantially in } 2020 \text {, that it is expected } \\
\text { to decline even more in } 2021 \text { and that the } \\
\text { pre-pandemic trajectory of improvement in life } \\
\text { expectancy is likely to slow down in at least the } \\
\text { next } 2 \text { years. Without enhanced coordination of } \\
\text { the pandemic response, expansion of testing and a } \\
\text { rapid increase in vaccination, Brazil will continue to } \\
\text { experience an unbearable loss in human life. }\end{array}$ \\
\hline
\end{tabular}

in $e_{0}$ in Brazil over 2 decades, $19 \%$ were lost due to COVID-19 (Supplementary Table 8). Among the states, Amazonas lost approximately $60 \%$ for both sexes and $68 \%$ among males. In 15 states (including the entire Southeast region), this loss was higher among males (Fig. 3a). A much higher loss was estimated for $e_{65}: 29 \%$ for both sexes in Brazil (Supplementary Table 9). Among males, two states, Amazonas and Pará, both in the North region, lost all that was gained over 2 decades (Fig. 3b).

As a result, estimated $e_{0}$ in Brazil in the presence of COVID-19 reflects levels observed in 2014 (Supplementary Table 10). Among the states, the largest setback was estimated for Amazonas and Pará (levels of 2006 for both sexes, 2008 and 2010 for females and 2005 and 2002 for males). The estimated setback for $e_{65}$ was overwhelming, equalling values last observed as far back as the early 2000s in most states in the North region and before 2000 in Amazonas, Pará and Goiás.

Provisional decline in life expectancy in 2021. In just the first 4 months of 2021, Brazil surpassed the number of COVID-19 deaths during all of 2020. This was the case for 12 of the 27 states (Fig. 4a). Therefore, we estimated the provisional decline in life expectancy in 2021 thus far; this estimate is based on the DT19 method noted earlier but, in this case, adding confirmed 2021 COVID-19 deaths to the deaths expected among those who did not die of COVID19, who are assumed to be subject to 2019 mortality rates for the remainder of 2021 (Supplementary Table 11).

The estimated decline in $2021 e_{0}$ is 1.78 years ( 1.86 years for males and 1.64 years for females). Because the 2021 estimates are based on deaths that occurred in only a 4-month period, the magnitudes of declines are not directly comparable with those for 2020 using the DT19 method (Supplementary Tables 5 and 6). However, for a given year, we can identify states with the largest reductions. Among the states, Amazonas, Rondônia, Roraima and Mato Grosso had the largest declines in $e_{0}$ in both 2020 and 2021 (Fig. 4b,c). For $e_{65}$, the decline in 2021 was estimated at 1.05 years for both sexes 

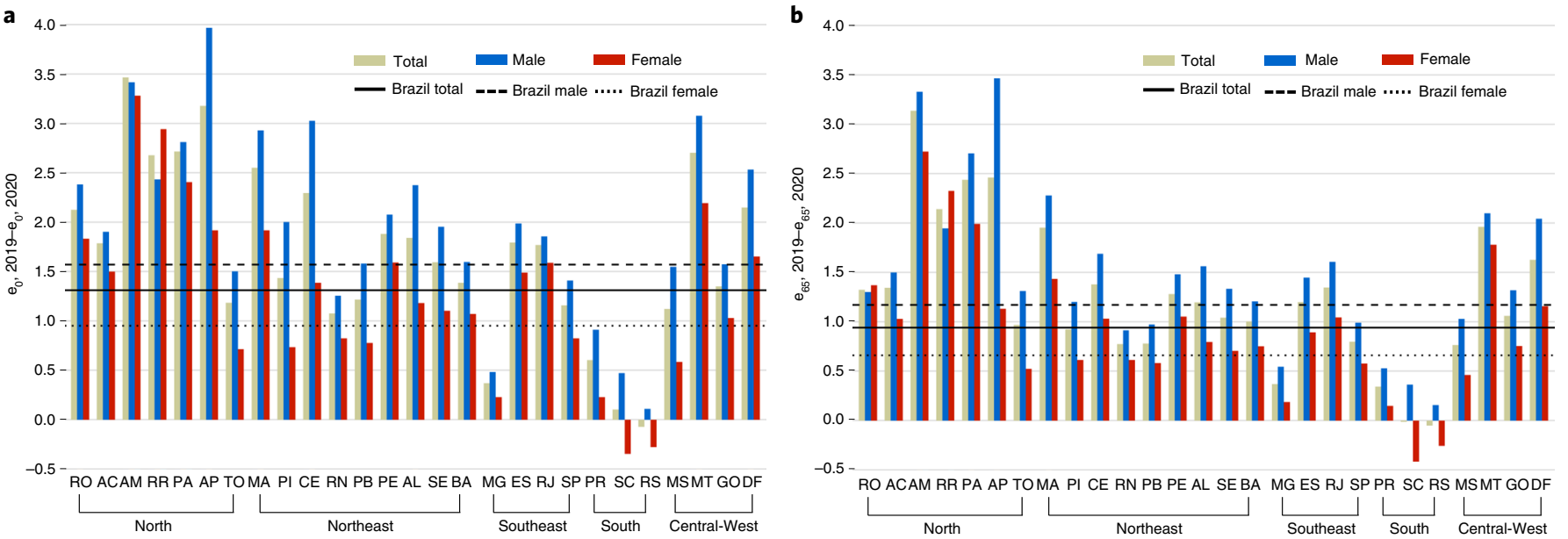

-0.5 - RO ACAM RR PA AP TOMA PI CE RN PB PE AL SEBA MG ES RJ SPPR SC RS MSMT GODF
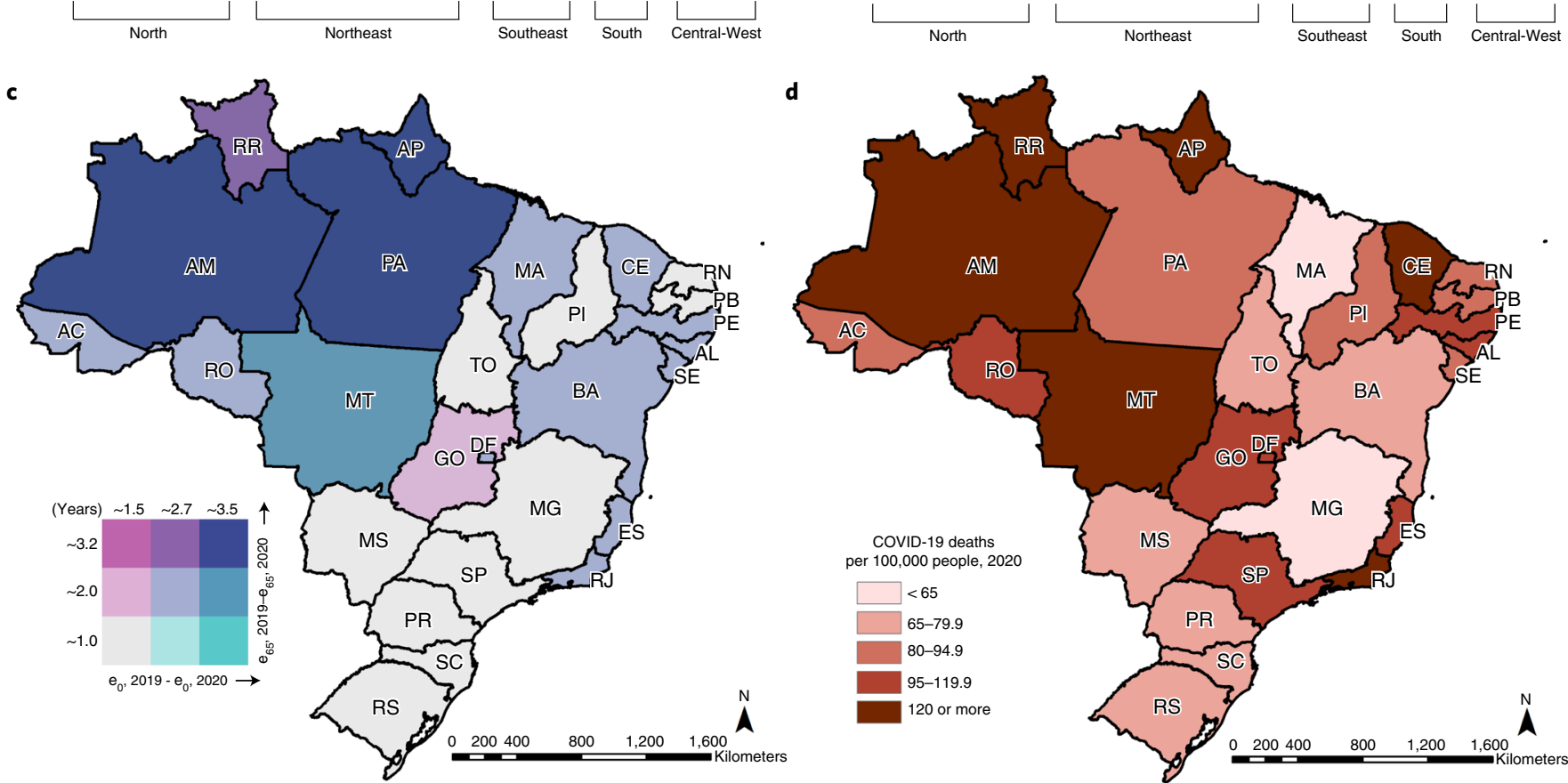

Fig. 1 Changes in life expectancy by state and sex. a, Estimated change in life expectancy at birth in 2020 based on the difference from life tables calculated for 2019 and 2020 by state and sex. State acronyms by region: North: $A C=A c r e, A P=A m a p a ́, A M=A m a z o n a s, P A=P a r a ́, R O=R o n d o ̂ n i a$, $\mathrm{RR}=$ Roraima and $\mathrm{TO}=$ Tocantins; Northeast: $\mathrm{AL}=$ Alagoas, $\mathrm{BA}=$ Bahia, $\mathrm{CE}=$ Ceará, $\mathrm{MA}=$ Maranhão, $\mathrm{PB}=$ Paraíba, $\mathrm{PE}=\mathrm{Pernambuco}, \mathrm{PI}=\mathrm{Piauí}, \mathrm{RN}=\mathrm{Rio}$ Grande do Norte and SE = Sergipe; Center-West: DF = Distrito Federal, GO=Goiás, MT= Mato Grosso and MS = Mato Grosso do Sul; Southeast: $\mathrm{ES}=$ Espírito Santo, MG = Minas Gerais, RJ = Rio de Janeiro and SP=São Paulo; South: PR= Paraná, RS = Rio Grande do Sul and SC=Santa Catarina. $\mathbf{b}$, Estimated change in $e_{65}$ in 2020 based on the difference from life tables calculated for 2019 and 2020 by state and sex. c, Bivariate choropleth map of the estimated change in $e_{0}$ and $e_{65}$ in 2020 based on the difference from life tables calculated for 2019 and 2020 by state. d, Number of COVID-19 deaths in 2020 per 100,000 people by state (Methods).

(Fig. 4d). As with 2020, for both $e_{0}$ and $e_{65}$, the lowest declines in 2021 were concentrated in the Northeast, whereas the South, which had relatively smaller declines in 2020 , is estimated to have a much greater loss in 2021.

\section{Discussion}

Our results quantify the effect of the COVID-19 death toll on life expectancy in Brazil. We show that life expectancy in the presence of COVID-19 is equivalent to levels observed in Brazil as far back as 20 or more years in some states. We calculate three sets of estimates of life expectancy decline but argue that those based on the difference in life expectancy between 2019 and 2020, which include all reported deaths in those 2 years, are the most defensible because they do not depend on accurate classification of cause of death, determination of whether the death was directly or indirectly due to COVID-19 or assumptions about independence among causes.
Nevertheless, the estimates might still suffer from incomplete and/ or delayed reporting of deaths, especially those for 2021, with potential variation in completeness across states. It is also the case that the difference in life expectancy between 2019 and 2020 could encompass secular changes unrelated to the pandemic. We surmise that the estimates derived from the decrement life table techniques (DT19 and DT20) are higher than those reported in the text because of additional biases related to violation of the assumption of independence between COVID-19 and other causes and misdiagnosis of cause of death.

When intense shocks like a pandemic or war occur, life expectancy drops, but it often rebounds quickly. This was the case with the 1918 influenza pandemic in the United States, when $e_{0}$ in 1919 was higher than in 1917, likely due, in part, to selective mortality of individuals with tuberculosis ${ }^{19}$. We argue that, in the case of COVID-19 in Brazil, the rebound will not happen in 2021, and the 

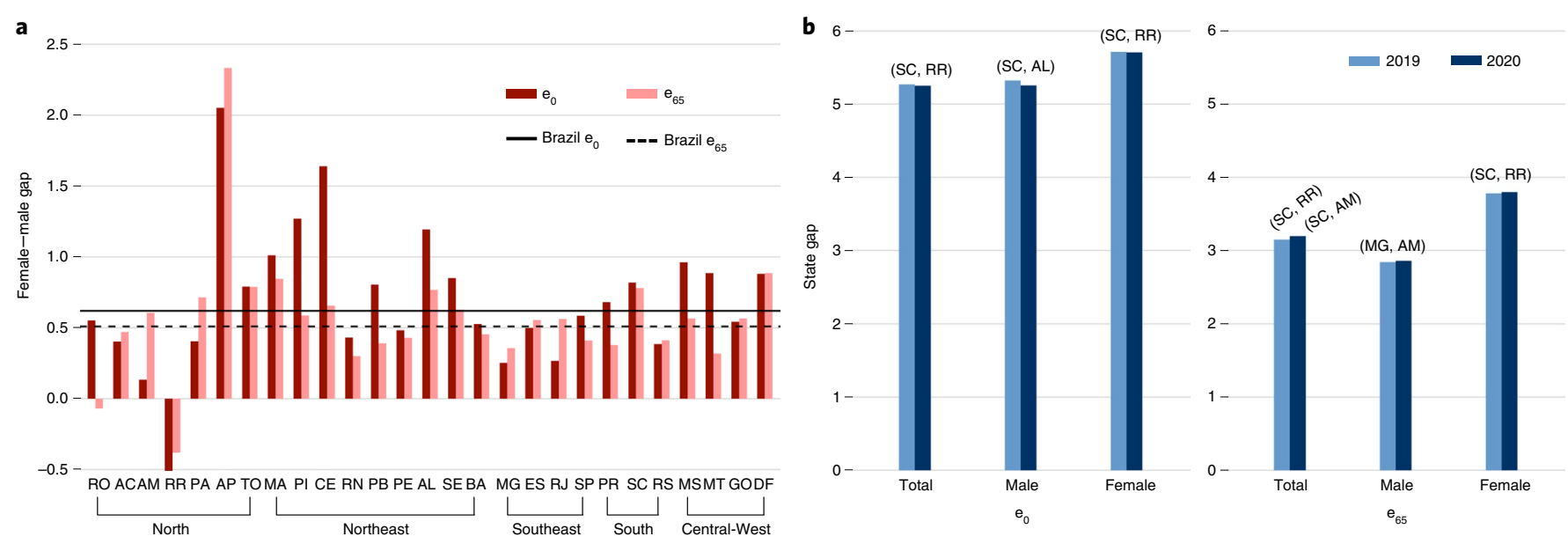

Fig. 2 Changes in gaps of $e_{0}$ and $e_{65}$ by state and sex. $a$, Change (in years) in the female-male gap in $e_{0}$ and $e_{65}$ based on the difference from life tables calculated for 2019 and 2020 by state and sex. Lines represent changes for Brazil. Bars, organized by major regions, show changes for the states. State acronyms by region: North: $\mathrm{AC}=\mathrm{Acre}, \mathrm{AP}=\mathrm{Amapá}, \mathrm{AM}=$ Amazonas, $\mathrm{PA}=$ Pará, $\mathrm{RO}=$ Rondônia, $\mathrm{RR}=$ Roraima and $\mathrm{TO}=$ Tocantins; $\mathrm{Northeast:}$ $\mathrm{AL}=$ Alagoas, $\mathrm{BA}=$ Bahia, $\mathrm{CE}=$ Ceará, $\mathrm{MA}=$ Maranhão, $\mathrm{PB}=$ Paraíba, $\mathrm{PE}=$ Pernambuco, $\mathrm{PI}=$ Piauí, $\mathrm{RN}=$ Rio Grande do Norte and $\mathrm{SE}=$ Sergipe; Center-West: $\mathrm{DF}=$ Distrito Federal, $\mathrm{GO}=$ Goiás, MT = Mato Grosso and MS= Mato Grosso do Sul; Southeast: ES=Espírito Santo, MG = Minas Gerais; RJ = Rio de Janeiro and SP = São Paulo; South: PR = Paraná, RS = Rio Grande do Sul and SC=Santa Catarina. b, Gap (in years) in state $e_{0}$ and $e_{65}$ in 2019 and 2020, calculated as the difference between the largest and smallest life expectancy among states (Methods). Labels above bars indicate the states with extreme (high and low) life expectancies in 2019 and 2020.
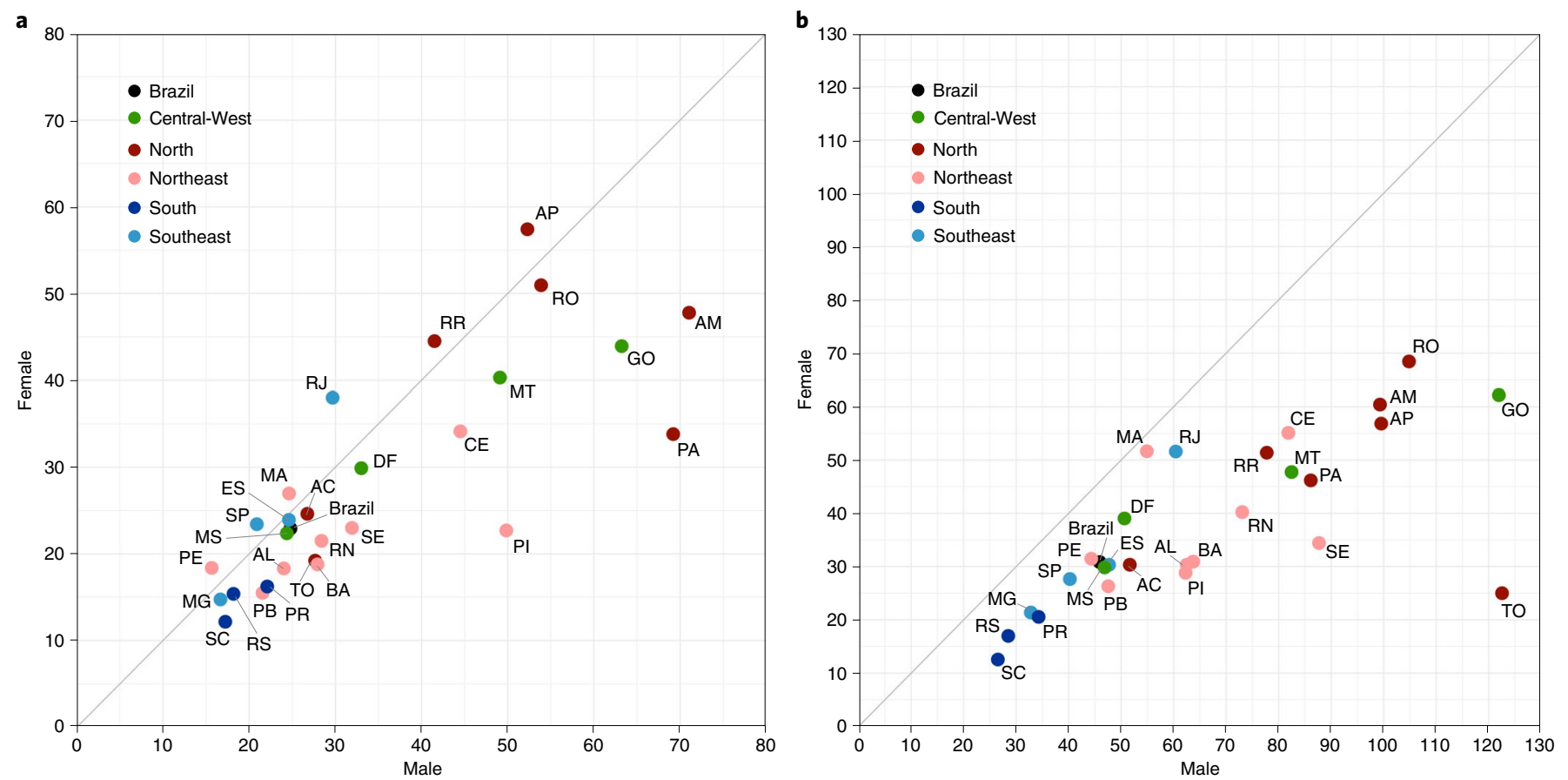

Fig. 3 | Loss in $e_{0}$ and $e_{65}$ by state and sex. Percentage loss due to COVID-19 mortality relative to increases in female and male $e_{0}(\mathbf{a})$ and $e_{65}(\mathbf{b})$ between 2000 and 2020 by state. States are colored according to major regions. State acronyms by region: North: $A C=A c r e, A P=A m a p a ́, A M=A m a z o n a s$, $\mathrm{PA}=$ Pará, $\mathrm{RO}=$ Rondônia, $\mathrm{RR}=$ Roraima and $\mathrm{TO}=$ Tocantins; Northeast: $\mathrm{AL}=$ Alagoas, $\mathrm{BA}=\mathrm{Bahia}, \mathrm{CE}=\mathrm{Ceará}, \mathrm{MA}=\mathrm{Maranh} a \tilde{\mathrm{o}}, \mathrm{PB}=\mathrm{Paraíba}$, $\mathrm{PE}=$ Pernambuco, $\mathrm{PI}=$ Piauí, $\mathrm{RN}=$ Rio Grande do Norte and $\mathrm{SE}=$ Sergipe; Center-West: DF = Distrito Federal, GO = Goiás, MT = Mato Grosso and MS = Mato Grosso do Sul; Southeast: ES = Espírito Santo, MG = Minas Gerais, RJ = Rio de Janeiro and SP=São Paulo; South: PR=Paraná, RS=Rio Grande do Sul and SC = Santa Catarina.

pre-pandemic trajectory of annual gains in $e_{0}$ will likely slow down. We offer five reasons as to why.

First, we estimate that COVID-19 deaths in the first 4 months of 2021 have already reduced $e_{0}$ by 1.8 years, and the ultimate effect on $2021 e_{0}$ will be even greater. After recording the highest number of monthly COVID-19 deaths in April 2021, transmission remains extremely high, with about 2,000 daily deaths but a very slow immunization rollout. As of 25 May 2021, 20 of the 27 capital cities have intensive care unit occupancy above $80 \%$ (half of those above $90 \%)^{20}$. As of 29 May 2021, the number of COVID-19 deaths in Brazil was $137 \%$ of those reported in 2020; in Amazonas, for every COVID-19 death in 2020, there have been 1.5 deaths in 2021 . 

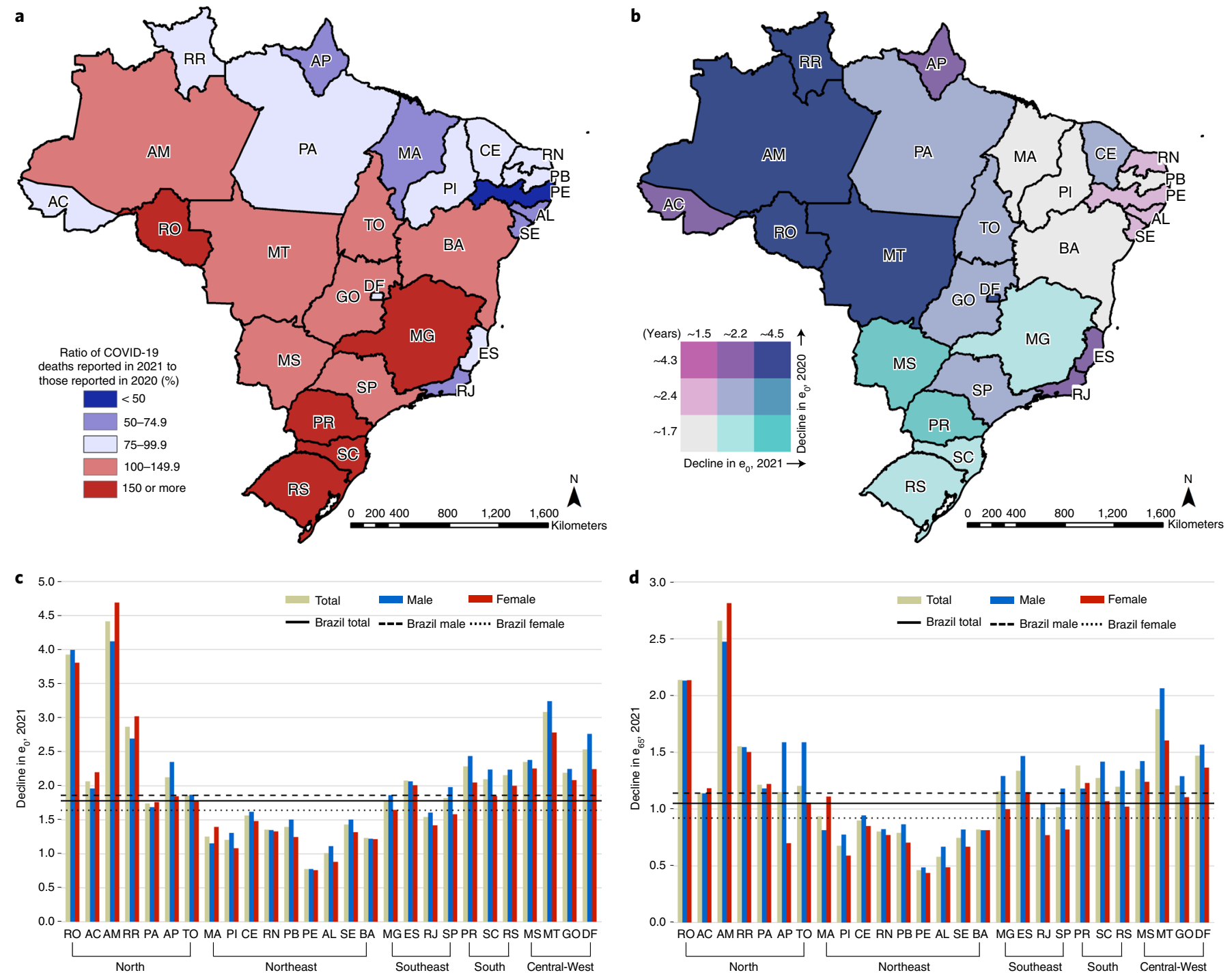

Fig. 4 | COVID-19 mortality in 2021 and changes in life expectancy by state and sex. a, Ratio of COVID-19 deaths reported in 2021 (January-April) to those reported in 2020 (\%). Numbers above 100 indicate more deaths in 2021 than 2020. State acronyms by region: North: $A C=A c r e, A P=A m a p a ́$, $\mathrm{AM}=$ Amazonas, $\mathrm{PA}=$ Pará, $\mathrm{RO}=$ Rondônia, $\mathrm{RR}=$ Roraima and $\mathrm{TO}=$ Tocantins; Northeast: $\mathrm{AL}=$ Alagoas, $\mathrm{BA}=\mathrm{Bahia}, \mathrm{CE}=\mathrm{Ceará}, \mathrm{MA}=\mathrm{Maranh}$ ão, $\mathrm{PB}=$ Paraíba, $\mathrm{PE}=$ Pernambuco, $\mathrm{PI}=$ Piauí, $\mathrm{RN}=$ Rio Grande do Norte and $\mathrm{SE}=$ Sergipe; Center-West: $\mathrm{DF}=$ Distrito Federal, $\mathrm{GO}=\mathrm{Goiás}, \mathrm{MT}=\mathrm{Mato}$ Grosso and MS = Mato Grosso do Sul; Southeast: ES=Espírito Santo, MG = Minas Gerais, RJ = Rio de Janeiro and SP=São Paulo; South: PR=Paraná, RS = Rio Grande do Sul and SC = Santa Catarina. b, Bivariate choropleth map of the estimated change in life expectancy at birth in 2020 and 2021 based on the DT19 method (Supplementary Tables 5 and 11). Estimated change in $e_{0}(\mathbf{c})$ and $e_{65}(\mathbf{d})$ in 2021.

Manaus, the capital of Amazonas, observed a very high attack rate after the first wave of the pandemic in 2020 (ref. ${ }^{21}$ ). In January 2021, Manaus witnessed one of the most tragic scenarios of overwhelmed hospital capacity, running out of not only hospital beds but also oxygen $^{22}$. A new variant of concern (P.1, now called Gamma), which emerged in the city in November 2020, is estimated to be $1.4-2.2$ times more transmissible than other lineages, and at least $17 \%$ of the P.1 infections in Manaus in 2021 were reinfections ${ }^{23,24}$. As of 23 May 2021, P.1 was the most prevalent strain in the country (92\% of the samples analyzed $)^{25}$. Also in May 2021, the first case of the Delta variant (B.1.617.2), first detected in India, was reported in Brazil ${ }^{26}$.

Second, COVID-19 disrupted primary care services in Brazil ${ }^{27}$. This compromised screening for cancer, with a reduction of about $35 \%$ in new diagnoses ${ }^{28}$. Child immunization was reduced, particularly among impoverished children in the North region ${ }^{29}$. Disruption in treatment and diagnosis of tuberculosis and HIV might increase mortality over the next 5 years $^{30}$. Overall health conditions of individuals with diabetes worsened in 2020 due to reduced physical activity, postponement of medical appointments and interruption in regular drug treatment ${ }^{31}$. These are some examples of deteriorating health conditions that not only will generate a higher demand for healthcare services but also might affect future mortality patterns.

Third, reports of long-term consequences of COVID-19 among survivors continue to emerge ${ }^{32,33}$, including fatigue and neurological, pulmonary and cardiovascular complications, among others. A large study showed a higher risk of death 6 months after COVID-19 diagnosis, even among those who did not require hospitalization $^{34}$. Therefore, COVID-19 sequelae might shorten individual lifespan.

Fourth, the economic crisis that hit Brazil in 2014 has contributed to increases in mortality ${ }^{35}$, poverty and inequality ${ }^{36}$. From April to December 2020, an emergency basic income program mitigated the challenges imposed by the pandemic ${ }^{37}$ (for example, unemployment), 
but this benefit ended in December 2020. Although some cities temporarily closed some businesses in response to the unprecedented COVID-19 surge in early 2021, no financial support was provided from January to March 2021. A more limited version of the basic income program was re-established in April 2021. COVID-19 exacerbated inequality, exposing the most vulnerable to food insecurity and severe hunger ${ }^{38,39}$.

Fifth, reductions in the health budget and changes in the health financing model are likely to affect health outcomes ${ }^{40}$. They might reduce access to and coverage of primary care and increase infant mortality and avoidable deaths. Ultimately, inequality might become worse, exacerbating an already distressing scenario due to COVID-19.

In a previous paper, we described the spatiotemporal patterns of the spread of COVID-19 cases and deaths in Brazil ${ }^{18}$. We showed that a largely unmitigated pandemic, in a context of local inequalities, resulted in a high and unequal mortality burden. The magnitude of the COVID-19 death toll was not homogenous across states and was associated with the pattern of spread ${ }^{18}$. We calculated the correlation between the speed of the spread of COVID-19 deaths (measured by the locational Hoover Index) ${ }^{18}$ and the decline in $e_{0}$. We found that the faster the speed at which COVID-19 spread across municipalities (a lower locational Hoover Index), the larger the changes in $e_{0}$ (Pearson correlation $=-0.724, P<0.001$ ).

In summary, the death toll of COVID-19 in Brazil has been catastrophic. State-level gains in longevity achieved over years or even decades were reversed by the pandemic. The lack of a coordinated, prompt and equitable response informed by science, as well as the promotion of disinformation, have been the hallmark of the current administration $^{27}$. In late April 2021, a parliamentary commission of inquiry was launched to investigate the government's handling of the pandemic response ${ }^{41}$. Brazil does not lack a universal healthcare system, a network of community health agents to target vulnerable communities, sufficient data and a capable cadre of researchers tirelessly advancing knowledge and informing policy. What it lacks is leadership commitment to save lives. After more than 195,000 lives were reported to have been lost in 2020 to COVID-19, no policy changes have appeared in 2021. As many countries speed up vaccination coverage and witness declines in cases and deaths, Brazil lags behind. Without a change in coordination of pandemic response, expansion of testing and a rapid increase in vaccination, Brazil will soon become a serious threat to national and global health security ${ }^{42}$. The consequences, sadly and unacceptably, will continue to be measured in human lives lost, and the future demographic consequences might be even worse than those reported here.

\section{Online content}

Any methods, additional references, Nature Research reporting summaries, source data, extended data, supplementary information, acknowledgements, peer review information; details of author contributions and competing interests; and statements of data and code availability are available at https://doi.org/10.1038/ s41591-021-01437-z.

Received: 19 April 2021; Accepted: 11 June 2021; Published online: 29 June 2021

\section{References}

1. Marinho, F. et al. Excess mortality in Brazil: a detailed description of trends in mortality during the COVID-19 pandemic. Vital Strategies. https://www. vitalstrategies.org/resources/excess-mortality-in-brazil-a-detailed-descriptionof-trends-in-mortality-during-the-covid-19-pandemic/ (2020).

2. Woolf, S. H., Chapman, D. A., Sabo, R. T., Weinberger, D. M. \& Hill, L. Excess deaths from COVID-19 and other causes, March-April 2020. JAMA 324, 510-513 (2020).

3. Barberia, L. G. \& Gómez, E. J. Political and institutional perils of Brazil's COVID-19 crisis. Lancet 396, 367-368 (2020).
4. Nuzzo, J. B., Bell, J. A. \& Cameron, E. E. Suboptimal US response to COVID-19 despite robust capabilities and resources. JAMA 324, 1391-1392 (2020).

5. Baqui, P., Bica, I., Marra, V., Ercole, A. \& van der Schaar, M. Ethnic and regional variations in hospital mortality from COVID-19 in Brazil: a cross-sectional observational study. Lancet Glob. Health 8 , E1018-E1026 (2020).

6. Holmes, L. et al. Black-white risk differentials in COVID-19 (SARS-COV2) transmission, mortality and case fatality in the United States: translational epidemiologic perspective and challenges. Int. J. Environ. Res. Public Health 17, 4322 (2020)

7. Smith, D. W. \& Bradshaw, B. S. Variation in life expectancy during the twentieth century in the United States. Demography 43, 647-657 (2006).

8. Andrasfay, T. \& Goldman, N. Reductions in 2020 US life expectancy due to COVID-19 and the disproportionate impact on the Black and Latino populations. Proc. Natl Acad. Sci. USA 118, e2014746118 (2021).

9. Palloni, A., Pinto, G. \& Beltrán-Sánchez, H. Two centuries of mortality decline in Latin America: from hunger to longevity. https://www.ssc.wisc.edu/ cdha/latinmortality/wp-content/uploads/book_Ch2.pdf (2015).

10. Simões, C. C. S. Breve histórico do processo demográfico. in Brasil: uma visão geográfica e ambiental no início do século XXI. 40-74 https://biblioteca. ibge.gov.br/index.php/biblioteca-catalogo?id=297884\&view=detalhes (IBGE, Coordenação de Geografia, 2016).

11. Vaupel, J. W., Villavicencio, F. \& Bergeron-Boucher, M.-P. Demographic perspectives on the rise of longevity. Proc. Natl Acad. Sci. USA 118, e2019536118 (2021).

12. Noronha, K. V. M. S. et al. The COVID-19 pandemic in Brazil: analysis of supply and demand of hospital and ICU beds and mechanical ventilators under different scenarios. Cad. Saúde Pública 36, e00115320 (2020).

13. Rocha, R. et al. Effect of socioeconomic inequalities and vulnerabilities on health-system preparedness and response to COVID-19 in Brazil: a comprehensive analysis. Lancet Glob. Health 9, e782-e792 (2021).

14. Pereira, A. K., Oliveira, M. S. \& Sampaio, T. S. Heterogeneidades das políticas estaduais de distanciamento social diante da COVID-19: aspectos políticos e técnico-administrativos. Revista de Administração Pública 54, 678-696 (2020).

15. Ranzani, O. T. et al. Characterisation of the first 250,000 hospital admissions for COVID-19 in Brazil: a retrospective analysis of nationwide data. Lancet Respir. Med. 9, 407-418 (2021).

16. Aburto, J. M. et al. Quantifying impacts of the COVID-19 pandemic through life expectancy losses: a population-level study of 29 countries. Preprint at medRxiv https://doi.org/10.1101/2021.03.02.21252772 (2021).

17. Heuveline, P. \& Tzen, M. Beyond deaths per capita: comparative COVID-19 mortality indicators. BMJ Open 11, e042934 (2021)

18. Castro, M. C. et al. Spatiotemporal pattern of COVID-19 spread in Brazil. Science 372, 821-826 (2021).

19. Noymer, A. \& Garenne, M. The 1918 influenza epidemic's effects on sex differentials in mortality in the United States. Popul. Dev. Rev. 26, 565-581 (2000).

20. Fundação Oswaldo Cruz. Boletim Extraordinário do Observatório Covid-19 Fiocruz. https://portal.fiocruz.br/sites/portal.fiocruz.br/files/documentos/ boletim_covid_2021_extraordinario_maio.pdf (2021).

21. Buss, L. F. et al. Three-quarters attack rate of SARS-CoV-2 in the Brazilian Amazon during a largely unmitigated epidemic. Science 371, 288-292 (2021).

22. Phillips, T. Covid eruption in Brazil's largest state leaves health workers begging for help. The Guardian. https://www.theguardian.com/world/2021/ jan/14/brazil-manaus-amazonas-covid-coronavirus (2021).

23. Faria, N. R. et al. Genomics and epidemiology of a novel SARS-CoV-2 lineage in Manaus, Brazil. Preprint at https://www.medrxiv.org/content/10.110 1/2021.02.26.21252554v1 (2021).

24. Faria, N. R. et al. Genomics and epidemiology of the P.1 SARS-CoV-2 lineage in Manaus, Brazil. Science 372, 815-821 (2021).

25. Fundação Oswaldo Cruz. Rede Genômica Fiocruz. Demonstrativos de linhagens e genomas SARS-CoV-2. http://www.genomahcov.fiocruz.br/ tabela-de-dados/ (2021).

26. Santos, M. C. et al. First reported cases of SARS-CoV-2 sub-lineage B.1.617.2 in Brazil: an outbreak in a ship and alert for spread. https://virological.org/t/ first-reported-cases-of-sars-cov-2-sub-lineage-b-1-617-2-in-brazil-an-outbreakin-a-ship-and-alert-for-spread/706 (2021).

27. Lotta, G., Wenham, C., Nunes, J. \& Pimenta, D. N. Community health workers reveal COVID-19 disaster in Brazil. Lancet 396, 365-366 (2020).

28. Marques, N. P. et al. Cancer diagnosis in Brazil in the COVID-19 era. Semin. Oncol. https://doi.org/10.1053/j.seminoncol.2020.12.002 (2021).

29. Silveira, M. F. et al. Missed childhood immunizations during the COVID-19 pandemic in Brazil: analyses of routine statistics and of a national household survey. Vaccine 39, 3404-3409 (2021).

30. Hogan, A. et al. Report 19: the potential impact of the COVID-19 epidemic on HIV, TB and malaria in low- and middle-income countries. https://doi. org/10.25561/78670 (Imperial College London, 2020). 
31. Barone, M. T. U. et al. The impact of COVID-19 on people with diabetes in Brazil. Diabetes Res. Clin. Pract. 166, 108304 (2020).

32. Abbasi, J. Researchers investigate what COVID-19 does to the heart. JAMA 325, 808-811 (2021)

33. Huang, C. et al. 6-month consequences of COVID-19 in patients discharged from hospital: a cohort study. Lancet 397, 220-232 (2021).

34. Al-Aly, Z., Xie, Y. \& Bowe, B. High-dimensional characterization of post-acute sequelae of COVID-19. Nature 594, 259-264 (2021).

35 . Hone, T. et al. Effect of economic recession and impact of health and social protection expenditures on adult mortality: a longitudinal analysis of 5565 Brazilian municipalities. Lancet Glob. Health 7, e1575-e1583 (2019).

36. Barbosa, R. J., Souza, P. H. G. F. \& Soares, S. S. D. Distribuição de Renda nos Anos 2010: uma década perdida para desigualdade e pobreza. https://www. ipea.gov.br/portal/index.php?option=com_content\&view=article\&id= 37022\&Itemid $=448$ (2020).

37. Duque, D. Auxílio Emergencial faz pobreza cair em plena pandemia. https://blogdoibre.fgv.br/posts/auxilio-emergencial-faz-pobreza-cair-em-plenapandemia (2020).
38. Carvalho, C. A., Viola, P. C. A. F. \& Sperandio, N. How is Brazil facing the crisis of food and nutrition security during the COVID-19 pandemic? Public Health Nutr. 24, 561-564 (2021)

39. Rede PENSSAN. VIGISAN. Inquérito Nacional sobre Insegurança Alimentar no Contexto da Pandemia da Covid-19 no Brasil. http://olheparaafome.com. br/VIGISAN_Inseguranca_alimentar.pdf (2021).

40. Castro, M. C. et al. Brazil's unified health system: the first 30 years and prospects for the future. Lancet 394, 345-356 (2019).

41. Phillips, T. Brazil begins parliamentary inquiry into Bolsonaro's Covid response. The Guardian. https://www.theguardian.com/world/2021/apr/27/ brazil-begins-parliamentary-inquiry-into-bolsonaros-covid-response (2021).

42. Ventura, D. F. L., Giulio, G. M. \& Rached, D. H. Lessons from the Covid-19 pandemic: sustainability is an indispensable condition of global health security. Ambiente \& Sociedade 23, e0108 (2020).

Publisher's note Springer Nature remains neutral with regard to jurisdictional claims in published maps and institutional affiliations.

() The Author(s), under exclusive licence to Springer Nature America, Inc. 2021 


\section{Methods}

Data. We used several data sources to estimate the changes in $e_{0}$ and $e_{65}$ due to COVID-19 by state and sex in Brazil. First, we obtained mid-year population projections for 2018-2020 and abridged life tables estimated for 2000-2020 by state, age and sex from the Brazilian Institute of Geography and Statistics (Instituto Brasileiro de Geografia e Estatística, or IBGE, in Portuguese) (https://www.ibge. gov.br/en/statistics/social/population/18176-population-projection.html).

Second, we used deaths from all causes by age, sex, cause of death and state of residence provided by the Mortality Information System from the Ministry of Health for $2019(n=1,345,543)$ and $2020(n=1,541,556)$. We removed 2,689 $(0.20 \%)$ and $2,722(0.18 \%)$ records in 2019 and 2020 , respectively, that did not have information on sex and/or age. Records with ill-defined, unspecified or unattended deaths (codes R99 and R98) in 2020 were treated as non-COVID-19 deaths (4.9\% $(75,484 / 1,541,556))$.

Third, because local health authorities have $60 \mathrm{~d}$ to report deaths from any cause, delayed death registration might be an issue in 2021, and, thus, for the first 4 months of 2021, we used confirmed COVID-19 deaths as reported by Brasil.io, which compiles epidemiological bulletins from the 27 state health departments. These records, aggregated at the state level, are publicly available by date on the website (https://brasil.io/covid19/). We abstracted death data on 18 May 2021, for all states, as reported through 30 April 2021 ( $n=209,458$ confirmed COVID-19 deaths). Because these data are not available by age and sex, we used de-identified publicly available data on severe acute respiratory illness (SARI) hospitalizations from the Influenza Epidemiological Surveillance Information System (Sistema de Informação de Vigilância Epidemiológica da Gripe, or SIVEP-Gripe, in Portuguese). The dataset provides the age and sex structure of hospitalized COVID-19 deaths, and frequent updates are made publicly available by the Ministry of Health (https://opendatasus.saude.gov.br/nl/dataset). Because in-hospital COVID-19 deaths represent $89 \%$ of all COVID-19 deaths reported in 2021, we use them to proxy for the age-sex distributions of all COVID-19 deaths.

Estimating total deaths. To estimate total deaths in the presence of COVID-19, we used different methodological approaches. For 2019 and 2020, our estimates include deaths from all causes registered in the Mortality Information System. For 2021, as the base case scenario, we calculated the number of deaths that would occur in the absence of COVID-19 $\left({ }_{n}^{*} D_{x}\right)$. To do this, we multiplied the age group-specific and sex-specific mortality rates from 2019 from each state by the corresponding projected population for March 2021. Next, we estimated total 2021 deaths, including COVID-19 confirmed deaths $\left({ }_{n} D_{x}^{C O V}\right)$, reported by Brasil. io. Here, we assumed that individuals who did not die of COVID-19 in the first 4 months of 2021 would be subject to the 2019 age group-specific and sex-specific mortality rates. Thus, we estimated total deaths in 2021, inclusive of COVID-19 deaths, as ${ }_{n} D_{x}=\left({ }_{n} K_{x}-{ }_{n} D_{x}^{C O V}\right)\left({ }_{n}^{*} M_{x}\right)+{ }_{n} D_{x}^{C O V}$, where ${ }_{n} D_{x}$ is the number of deaths estimated to occur in 2021 in the age range $x$ to $x+n ;{ }_{n} K_{x}$ is the population at risk in the age range $x$ to $x+n ;{ }_{n}^{*} M_{x}$ are age-specific mortality rates in the absence of COVID-19 (assumed to be 2019 mortality rates); and ${ }_{n} D_{x}^{C O V}$ is the number of confirmed COVID-19 deaths. For all intervals except ages $0-1,1-5$ and $90+$, the interval length $n$ is 5 years wide.

Estimating person-years lived and period rates. Estimates of period mortality rates require an estimate of the population exposed to the risk of dying. Usually, the mid-year population is a good approximation of person-years lived during the year. However, in the presence of COVID-19, this assumption might not hold because deaths were unevenly distributed over the year. Also, demographic projections did not account for the pandemic context and might have overestimated population size.

To calculate person-years for 2020, we first interpolated population projections, assuming exponential growth by age, sex and state, for the first day of each month in 2020 . We assumed that those dying in a given month from any cause contributed, on average, $0.5 / 12$ person-years, whereas the contribution of survivors was $1 / 12$ person-years. To compute the total persons-years lived for 2020 , we added the monthly contributions. To avoid inconsistencies between life tables estimated for 2019 and 2020, we applied the same methodology to 2019. We approximated the population at risk in 2021 by interpolating IBGE population projections to the mid-analysis period (1 March 2021).

Changes in life expectancy. We used three approaches to assess changes in life expectancy due to COVID-19. First, as our main specification, we constructed period life tables that considered deaths by state, sex and age group. We used death rates from all causes (including COVID-19) to calculate single-decrement life tables in 2019 and 2020 . We did not make any corrections for the under-registration of deaths. Over the last decades, the completeness of death registration has improved steadily in Brazil ${ }^{43}$, and data completeness is likely to be similar for 2019 and 2020. Therefore, our estimates would not be seriously affected by missing deaths unless a different pattern of errors emerges in 2020. To the extent that correction factors are approximately equal for 2019 and 2020, our estimates are not seriously affected by missing deaths. For each state and sex, we calculated the difference between the two life tables to estimate reductions in $e_{0}$ and $e_{65}$ due to COVID-19 (Supplementary Tables 1 and 2). We also used these period life tables to calculate the female-male gap in $e_{0}$ and $e_{65}$ (Supplementary Table 7); the difference between the highest and lowest state life expectancies; the loss due to COVID19 relative to increases in $e_{0}$ and $e_{65}$ (by sex and state) over the past two decades (2000-2020) (Supplementary Tables 8 and 9); and the setback in life expectancy due to COVID-19 identified by the years when the life expectancies estimated for 2020 and 2021 were last observed (Supplementary Table 10).

Second, we calculated cause-deleted life tables for 2020 (DT20), which examine the consequences of eliminating COVID-19 mortality from 2020 deaths ${ }^{44}$. We calculated ${ }_{n} R_{x}$, the age-specific and sex-specific ratio of deaths from all causes other than COVID-19 to deaths inclusive of COVID-19.

Third, for both 2020 and 2021, we calculated life tables based on the addition of COVID-19 mortality to the mortality pattern of 2019 (DT19). Previous studies used this approach to estimate life tables in the presence of COVID-19 (refs. ${ }^{8,17}$ ). For the base case scenario (absence of COVID-19), we used mortality rates reported in 2019, which we treated as cause-deleted life tables (that is, there were no deaths from COVID-19 in 2019), and applied these to the population at risk to obtain expected deaths in the absence of COVID-19. Expected deaths in the presence of COVID-19 are calculated by assuming that individuals who do not die of COVID-19 in 2020 and 2021 are subject to the mortality rates of 2019. For DT19, ${ }_{n} R_{x}$ is calculated as the ratio of expected deaths in the absence of COVID-19 to expected deaths in the presence of COVID-19.

For both DT20 and DT19, after estimating the ratio of non-COVID-19 deaths to all-cause deaths, we then used this ratio to estimate the counterfactual life tables in which COVID-19 was eliminated and COVID-19 was included, respectively. We made the assumption of proportionality between forces of decrement from cause $i$ (or all causes except $i$ ) and the force of decrement from all other causes combined $^{8,45}$. (In contrast to this assumption, the potential dependence between COVID-19 and other causes might lead to modified probabilities of dying from other causes if COVID-19 were eliminated or added as a cause of death.) We applied standard life table relationships to complete these counterfactual life tables ${ }^{44}$. We calculated the probability of surviving from age $x$ to age $x+n\left({ }_{n} p_{x}\right)$, the probability of dying between age $x$ and $x+n\left({ }_{n} q_{x}\right)$ and the average person-years lived in the interval by those dying in the interval $\left({ }_{n} a_{x}\right)$ :

$$
\begin{gathered}
{ }_{n} \boldsymbol{R}_{\boldsymbol{x}}=\frac{{ }_{n}^{*} D_{\boldsymbol{x}}}{{ }_{n} \boldsymbol{D}_{\boldsymbol{x}}} \\
{ }_{n} \boldsymbol{p}_{\boldsymbol{x}}=\boldsymbol{e}^{\left(\frac{1}{{ }_{n} \boldsymbol{R}_{x}} * \log \left({ }_{n}^{*} p_{x}\right)\right)} \\
{ }_{n} \boldsymbol{q}_{\boldsymbol{x}}=1-{ }_{n} \boldsymbol{p}_{\boldsymbol{x}} \\
{ }_{n} \boldsymbol{a}_{\boldsymbol{x}}=\boldsymbol{n}+\frac{1}{{ }_{n} \boldsymbol{R}_{\boldsymbol{x}}} * \frac{{ }_{n}^{*} \boldsymbol{q}_{\boldsymbol{x}}}{{ }_{n} \boldsymbol{q}_{\boldsymbol{x}}} *\left({ }_{n}^{*} \boldsymbol{a}_{\boldsymbol{x}}-\boldsymbol{n}\right) \\
\infty \boldsymbol{a}_{90}={ }_{\infty}^{*} \boldsymbol{a}_{90} * \infty \boldsymbol{R}_{90}
\end{gathered}
$$

where ${ }^{*}$ indicates that the measure is from the life table that does not contain COVID-19 as a cause of death.

We estimated reductions in $e_{0}$ and $e_{65}$ due to COVID-19, for each state and sex, from the difference between the 2020 period life table and the DT20 estimates (Supplementary Tables 3 and 4), between the 2019 period life table and the DT19 estimates for 2020 (Supplementary Tables 5 and 6) and between the 2019 period life table and the DT19 estimates for 2021 (Supplementary Table 11).

We performed all demographic analyses in Microsoft Excel version 16.44 and data cleaning and processing in Stata version 15.1 (Stata Corporation) and $\mathrm{R}$ version 4.0.0 (2020). We created data visualizations in $\mathrm{R}$, ArcMap version 10.8 (ESRI) and Adobe Illustrator CS6.

Reporting Summary. Further information on research design is available in the Nature Research Reporting Summary linked to this article.

\section{Data availability}

The data required to reproduce the results presented in this paper are available at https://github.com/mcastrolab/Brazil-Covid19-e0-change/tree/main/data.

\section{Code availability}

The calculation and figure codes required to reproduce the results presented in this paper are available at https://github.com/mcastrolab/Brazil-Covid19-e0-change/ tree/main/code.

\section{References}

43. IBGE. Tábuas Abreviadas de Mortalidade por Sexo e Idade. Brasil, Grandes Regiões e Unidades da Federação 2010. in Estudos e Pesquisas. Informação Demográfica e Socioeconômica. Número 30116 (Instituto Brasileiro de Geografia e Estatística-IBGE, Diretoria de Pesquisas, Coordenação de População e Indicadores Sociais, 2013). 
44. Preston, S., Heuveline, P. \& Guillot, M. Demography: Measuring and Modeling Population Processes (Wiley-Blackwell, 2000).

45. Chiang, C. L. Introduction to Stochastic Processes in Biostatistics (Wiley, 1968).

\section{Acknowledgements}

T.A. is supported by the National Institute on Aging (grant no. T32 AG000037). C.M.T. is supported by the Brazilian National Council for Scientific and Technological Development. M.C.C., S.G.K. and S.K. are supported by the National Institutes of Health (grant no. 2U19AI089681-08).

\section{Author contributions}

M.C.C. and N.G. conceived the research. M.C.C., N.G., C.M.T. and T.A. defined the methodology. T.A., S.G. and S.K. wrote the codes for analysis. M.C.C. and S.G. conducted the formal analysis. M.C.C., N.G., T.A. and C.M.T. interpreted the data. M.C.C. and S.G. conducted data curation. M.C.C. and S.K. produced all visualization.
M.C.C. and C.M.T. wrote the first draft of the manuscript. All authors contributed to the interpretation of results and manuscript editing.

\section{Competing interests}

The authors declare no competing financial interests.

\section{Additional information}

Supplementary information The online version contains supplementary material available at https://doi.org/10.1038/s41591-021-01437-z.

Correspondence and requests for materials should be addressed to M.C.C.

Peer review information Nature Medicine thanks Pedro Hallal, Usama Bilal and Vladimir Canudas Romo for their contribution to the peer review of this work. Jennifer Sargent was the primary editor on this article and managed its editorial process and peer review in collaboration with the rest of the editorial team.

Reprints and permissions information is available at www.nature.com/reprints. 


\section{Reporting Summary}

Nature Research wishes to improve the reproducibility of the work that we publish. This form provides structure for consistency and transparency in reporting. For further information on Nature Research policies, see our Editorial Policies and the Editorial Policy Checklist.

\section{Statistics}

For all statistical analyses, confirm that the following items are present in the figure legend, table legend, main text, or Methods section.

n/a Confirmed

Х $\square$ The exact sample size $(n)$ for each experimental group/condition, given as a discrete number and unit of measurement

$\triangle \square$ A statement on whether measurements were taken from distinct samples or whether the same sample was measured repeatedly

$\square$ The statistical test(s) used AND whether they are one- or two-sided

$\triangle \square$ Only common tests should be described solely by name; describe more complex techniques in the Methods section.

Х $\square$ A description of all covariates tested

\ $\square$ A description of any assumptions or corrections, such as tests of normality and adjustment for multiple comparisons

$\square$ A full description of the statistical parameters including central tendency (e.g. means) or other basic estimates (e.g. regression coefficient)

$\triangle \square$ AND variation (e.g. standard deviation) or associated estimates of uncertainty (e.g. confidence intervals)

For null hypothesis testing, the test statistic (e.g. $F, t, r$ ) with confidence intervals, effect sizes, degrees of freedom and $P$ value noted

Q Give P values as exact values whenever suitable.

Х $\square$ For Bayesian analysis, information on the choice of priors and Markov chain Monte Carlo settings

Х $\square$ For hierarchical and complex designs, identification of the appropriate level for tests and full reporting of outcomes

Х $\square$ Estimates of effect sizes (e.g. Cohen's $d$, Pearson's $r$ ), indicating how they were calculated

Our web collection on statistics for biologists contains articles on many of the points above.

\section{Software and code}

Policy information about availability of computer code

Data collection All data used to run the analysis are available at https://github.com/mcastrolab/Brazil-Covid19-e0-change/tree/main/data

Data analysis We performed all demographic analyses in Microsoft Excel v.16.44, and data cleaning and processing in Stata v.15.1 (Stata Corp., College Station, TX, USA) and R v.4.0.0 (R core team, 2020). We created data visualizations in R, ArcMap v.10.8 (ESRI; Redlands, CA), and Adobe

Illustrator CS6. All codes used to run the analysis are available at https://github.com/mcastrolab/Brazil-Covid19-e0-change/tree/main/code

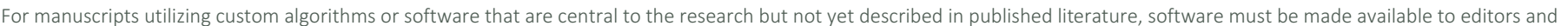

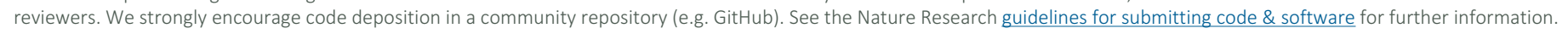

\section{Data}

Policy information about availability of data

All manuscripts must include a data availability statement. This statement should provide the following information, where applicable:

- Accession codes, unique identifiers, or web links for publicly available datasets

- A list of figures that have associated raw data

- A description of any restrictions on data availability

Several sources were used: https://www.ibge.gov.br/en/statistics/social/population/18176-population-projection.html, https://brasil.io/covid19/, https:// opendatasus.saude.gov.br/nl/dataset. All data used to run the analysis are available at https://github.com/mcastrolab/Brazil-Covid19-e0-change/tree/main/data 
Please select the one below that is the best fit for your research. If you are not sure, read the appropriate sections before making your selection. \Life sciences Behavioural \& social sciences Ecological, evolutionary \& environmental sciences

\section{Life sciences study design}

All studies must disclose on these points even when the disclosure is negative.
Sample size
We used data on all deaths reported in the country. No sample involved

Data exclusions

We removed 2,689 (0.20\%) and 2,722 (0.18\%) deaths in 2019 and 2020, respectively, that did not have information on sex and/or age.

Replication

N/A

Randomization

N/A

Blinding

N/A

\section{Reporting for specific materials, systems and methods}

We require information from authors about some types of materials, experimental systems and methods used in many studies. Here, indicate whether each material, system or method listed is relevant to your study. If you are not sure if a list item applies to your research, read the appropriate section before selecting a response.

\begin{tabular}{|c|c|c|c|}
\hline \multicolumn{2}{|r|}{ Materials \& experimental systems } & \multicolumn{2}{|c|}{ Methods } \\
\hline $\mathrm{n} / \mathrm{a}$ & Involved in the study & $\mathrm{n} / \mathrm{a}$ & Involved in the study \\
\hline \ & Antibodies & X & $\square$ ChIP-seq \\
\hline$\bigotimes$ & Eukaryotic cell lines & Х & $\square$ Flow cytometry \\
\hline$\bigotimes$ & Palaeontology and archaeology & Х & $\square$ MRI-based neuroimaging \\
\hline$\bigotimes$ & $\square$ Animals and other organisms & & \\
\hline Х & $\square$ Human research participants & & \\
\hline$\bigotimes$ & $\square$ Clinical data & & \\
\hline Х & $\square$ Dual use research of concern & & \\
\hline
\end{tabular}

